\title{
Editorial:
}

\section{El ODS 4 (y el 16) como meta para los próximos años}

\author{
SDG 4 (and 16) as a goal for the next years
}

\author{
F. Javier Murillo * 1 \\ Cynthia Duk ${ }^{2}$ \\ ${ }^{1}$ Universidad Autónoma de Madrid \\ ${ }^{2}$ Universidad Central de Chile
}

El 25 septiembre de 2015, durante la reunión de la Organización para las Naciones Unidas (ONU), 193 líderes mundiales se comprometieron a alcanzar la Agenda 2030 para el Desarrollo Sostenible. En la misma se incluye un conjunto de 17 Objetivos de Desarrollo Sostenible (ODS) de aplicación universal que marcan la meta de actuación para los siguientes 15 años. Estos ODS buscan poner fin a la pobreza, luchar contra la desigualdad y la injusticia y hacer frente al cambio climático, asegurando la prosperidad para todos como parte de una nueva agenda de desarrollo sostenible.

De estos 17 objetivos hay uno que nos interesa en el marco de la Revista Latinoamericana de Educación Inclusiva: el ODS 4. El mismo está formulado en los siguientes términos: "Garantizar una educación inclusiva, equitativa y de calidad y promover oportunidades de aprendizaje durante toda la vida para todos” y se confía la coordinación de su logro a la $\mathrm{UNESCO}^{1}$. Tiene dos poblaciones objeto preferentes: de un lado, África Subsahariana y Asia Meridional; y, de otro, personas vulnerables tales como las personas con discapacidad, los pueblos indígenas, los niños y niñas refugiados y aquellos que están en situación de pobreza en zonas rurales.

El ODS 4 se desglosa en siete metas, y tres medios de implementación. Las metas son las siguientes:

1. Para 2030, velar por que todas las niñas y todos los niños terminen los ciclos de la enseñanza primaria y secundaria, que ha de ser gratuita, equitativa y de calidad y producir resultados escolares pertinentes y eficaces.

2. Para 2030, velar por que todas las niñas y todos los niños tengan acceso a servicios de atención y desarrollo en la primera infancia y a una enseñanza preescolar de calidad, a fin de que estén preparados para la enseñanza primaria.

3. Para 2030, asegurar el acceso en condiciones de igualdad para todos los hombres y las mujeres a una formación técnica, profesional y superior de calidad, incluida la enseñanza universitaria.

4. Para 2030, eliminar las disparidades de género en la educación y garantizar el acceso en condiciones de igualdad de las personas vulnerables, incluidas las

${ }^{1}$ http://www.un.org/sustainabledevelopment/es/education/

*Contacto: javier.murillo@uam.es

ISSN: 0718-7378

www.rinace.net/rlei/ 
personas con discapacidad, los pueblos indígenas y los niños en situaciones de vulnerabilidad, a todos los niveles de la enseñanza y la formación profesional.

5. Para 2030, aumentar sustancialmente el número de jóvenes y adultos que tienen las competencias necesarias, en particular técnicas y profesionales, para acceder al empleo, el trabajo decente y el emprendimiento.

6. Para 2030, garantizar que todos los jóvenes y al menos una proporción sustancial de los adultos, tanto hombres como mujeres, tengan competencias de lectura, escritura y aritmética.

7. Para 2030, garantizar que todos los alumnos adquieran los conocimientos teóricos y prácticos necesarios para promover el desarrollo sostenible, entre otras cosas mediante la educación para el desarrollo sostenible y la adopción de estilos de vida sostenibles, los derechos humanos, la igualdad de género, la promoción de una cultura de paz y no violencia, la ciudadanía mundial y la valoración de la diversidad cultural y de la contribución de la cultura al desarrollo sostenible, entre otros medios.

Resulta curioso que, a pesar de que este objetivo comience destacando la educación inclusiva -“Garantizar una educación inclusiva...."-, ésta se presente algo difusa en su desarrollo y en las metas en las que se concreta. De hecho, es en la meta 4 donde más explícitamente se habla de la equidad y la inclusión, pero se refiere exclusivamente al acceso a la educación: “...garantizar el acceso en condiciones de igualdad de las personas vulnerables, incluidas las personas con discapacidad, los pueblos indígenas y los niños en situaciones de vulnerabilidad, a todos los niveles de la enseñanza y la formación profesional’.

Sin dejar de valorar la existencia y pertinencia de los Objetivos de Desarrollo Sostenible, no podemos dejar de mostrarnos un poco decepcionados por la falta de ambición del oDs 4 respecto a la educación inclusiva. Sin duda, garantizar el acceso de todas y cada una de las personas a la educación, especialmente aquellas que se han mantenido tradicionalmente excluidas o con más dificultades para su acceso como son las personas con discapacidad, los pueblos indígenas, y los niños y niñas en situación de vulnerabilidad es un importante avance. Pero no es suficiente. Una educación inclusiva exige necesariamente que todos y cada uno de los niños, niñas y adolescentes, además de tener acceso a la educación, participen y aprendan.

Efectivamente, es necesario garantizar la participación de todos y todas en su proceso educativo y en la vida de la comunidad escolar. Por participar no hacemos referencia solo a estar presentes de forma activa en las diferentes actividades que se organicen, nos referimos también a la importancia de ser reconocidos, de opinar y colaborar en la toma de decisiones sobre aquellas cuestiones que les afecten. Este elemento, básico para conseguir una escuela inclusiva y socialmente justa, es demasiadas veces ignorado por planteamientos excesivamente paternalistas.

$\mathrm{Y}$, por supuesto, es necesario garantizar que todos y cada uno de los y las estudiantes aprendan. De nada sirve estar escolarizado si no se aprende. Un aprendizaje que desarrolle al máximo las potencialidades de cada persona, pero siempre bajo el planteamiento de que son las personas que más lo necesitan las que reciban una mayor y mejor atención educativa.

Sin embargo, hemos hecho una pequeña trampa en nuestro discurso, el ODS 4 habla de igualdad de oportunidades y alcanzar niveles formativos equivalentes, pero se centra 
fundamentalmente en la igualdad de género. Definitivamente aplaudimos este enfoque, pero de nuevo, lo consideramos insuficiente. Todas las personas, independientemente de su origen social, grupo cultural de pertenencia, lugar de nacimiento, capacidad, identidad de género u orientación sexual deben tener esa igualdad educativa, una igualdad basada en el reconocimiento y valoración de la diversidad como elemento esencial para la construcción de comunidades educativas más inclusivas y equitativas.

Nuestro interés en los ODS, aun siendo prioritario el número 4, no acaba en él. El ODS 16 dice así "Promover sociedades justas, pacíficas e inclusivas". Y aunque este oDs se concreta en metas algo alejadas de la educación, sí que nos ponen sobre la mesa algo que quizás se nos olvida en la educación inclusiva: el para qué. Una educación inclusiva para una sociedad inclusiva. Si no miramos más allá de las escuelas y con nuestras acciones no buscamos incidir directamente en un cambio social, solo conseguiremos inútiles oasis de inclusión.

Los Objetivos de Desarrollo Sostenible son una excelente iniciativa de la comunidad internacional para focalizar esfuerzos en 17 objetivos. Aun cuando se nos queden escasos, creemos que es una excelente oportunidad para marcar el camino. Nos quedan 13 años de duro trabajo para que en el 2030 de verdad podamos decir que estamos en un mundo mejor, y que nuestro trabajo logrando una educación verdaderamente inclusiva, ha contribuido a ello. 